\title{
AMAR
}

AMAR (Andalas Management Review)

Vol. 4, No. 1 (2020) 82-99

The Management Institute, Faculty of Economics, Universitas Andalas

ISSN (Print) 2476-9282 | ISSN (Online) 2548-155X

\section{Persepsi Mahasiswa tentang Sistem Informasi Akademik Perguruan Tinggi}

\author{
Lucy Chairoela, Mellyna Eka Yan Fitrib, Lasti Yossi Hastinic \\ $a, b, c$ Program Studi Manajemen Fakultas Ekonomi dan Bisnis Universitas Dharma Andalas, \\ lucy.chairoel69@gmail.com
}

\begin{abstract}
A qualified college is one that has a good SIA for students, lecturers, and the academic administration department of the university. Good quality of SIA facilities will be an added value for the higher education itself and ultimately become a major service for higher education. The objective of this research is to find out the extent of students' perceptions of academic information system services in tertiary institutions. The sample collection technique in this study uses non-probability sampling because of cost, time, and acceptance of the results. From the non-probability sampling design, this research uses a purposive sampling technique with the criteria being students of the faculty of economics and business management study program S1 who have used SIA at least 2 times. And the number of samples obtained were 61 respondents. Five variables measure students' perceptions about the performance of SIA Online, namely the variables of ease of use, the usefulness of use, attitude of use, the behavior of users, and actual users. The descriptive data analysis technique used is Importance Performance Analysis (IPA) analysis to measure service mapping to know students' perceptions of the quality of AIS services and analyze the range of criteria to determine the position of the service quality. In terms of use benefit variables, it is a top priority to improve because is in the first quadrant in the IPA Quadrant and the use benefit variable has a score of 152 which is in the unsatisfactory range.

Keywords: perception, academic information system
\end{abstract}

\section{PENDAHULUAN}

Pada zaman sekarang perkembangan teknologi semakin maju, sehingga setiap orang tidak terlepas dari penggunaan teknologi. Dikarenakan teknologi dapat membantu dan memudahkan pekerjaan manusia. Kondisi ini berdampak positif bagi kehidupan manusia. Perkembangan teknologi ini tidak hanya di bidang bisnis tetapi juga di bidang pendidikan. Teknologi yang banyak digunakan di bidang pendidikan sering disebut dengan sistem informasi akademik (SIA). Kemampuan sistem informasi yang baik adalah informasi yang dibutuhkan akurat, cepat, dan efisien dan memberikan manfaat sesuai dengan kebutuhan yang diinginkan oleh individu yang berkepentingan. Sedangkan kesuksesan sistem informasi diperlihatkan dimana sistem informasi dapat memberikan kontribusi pada organisasi dalam pencapaian tujuannya. Sistem informasi dikatakan gagal apabila kurang atau tidak dimanfaatkan oleh user (Kristiawan, Sunarto, Sabandi, 2016). Agar sistem informasi 
digunakan secara optimal, maka diperlukan evaluasi terhadap sistem tersebut. Dikarenakan investasi untuk menerapkan sistem informasi ini sangat besar.

Organisasi di bidang pendidikan ini salah satunya adalah perguruan tinggi (PT). Perguruan tinggi yang baik adalah yang memiliki SIA yang baik untuk mahasiswa, dosen dan bagian administrasi akademik perguruan tinggi. Fasilitas SIA yang berkualitas akan menjadi nilai tambah bagi perguruan tinggi itu sendiri dan akhirnya manjadi suatu layanan yang utama bagi perguruan tinggi. Sistem informasi akademik adalah suatu sistem yang dirancang untuk keperluan pengeloaan data-data akademik dengan penerapan teknologi komputer baik hardware maupun software sehingga seluruh proses kegiatan akademik dapat terkelola menjadi informasi yang bermanfaat dalam pengelolaan manajemen perguruan tinggi dan pengambilan keputusan-keputusan bagi pengambil keputusan atau top manajemen di lingkungan perguruan tinggi (https://sevima.com/ didownload tgl 20/06/2019).

Penggunaan SIA pada saat ini sudah menjadi kewajiban bagi setiap mahasiswa, tetapi masih ada mahasiswa yang mengalami kendala dalam mengakses dan menggunakannya. Hal ini kemungkinan disebabkan oleh penggunaan yang sulit, fasilitas penunjang yang masih kurang, dan ketidaksesuaian sistem dengan kebutuhan kampus. Penelitian yang dilakukan oleh Sultono et al (2015) bahwa ada pengaruh kualitas pelayanan sistem informasi akademik terhadap kepuasan penggunanya di Universitas Pendidikan Indonesia. Dalam penelitian ini menjelaskan bahwa terjadinya kesenjangan antara harapan dan hasil yang dirasakan walaupun rata-rata keseluruhan menunjukkan rasa yang puas. Temuan dari penelitian ini menunjukkan perlu evaluasi secara berkala dari pengelola sistem informasi akademik dengan melibatkan pengguna agar dapat memastikan bahwa kebutuhan pengguna terpenuhi. Perguruan tinggi swasta Sumatera Barat khususnya kota Padang pada umumnya sudah menggunakan sistem informasi akademik agar interaksi mahasiswa, dosen dan karyawan perguruan tinggi dapat terlaksana dengan lancar dan baik.

Dari uraian diatas, maka penulis tertarik untuk melihat persepsi mahasiswa terhadap penggunaan SIA di universitas yang ada di kota Padang. Dengan asumsi universitas tersebut, sudah mempunyai SIA yang dapat diakses dimana saja. Dari uraian latar belakang di atas memperlihatkan masalah yang terjadi adalah bagaimana persepsi mahasiswa terhadap pelayanan sistem informasi akademik pada universitas swasta di Kota Padang. Tujuan yang didapat dari penelitian ini adalah untuk mengetahui sebatas mana persepsi mahasiswa terhadap pelayanan sistem informasi akademik pada universitas di Kota Padang. 


\subsection{Teori TAM}

Technology Acceptance Model (TAM) dikembangkan oleh Davis (Jogiyanto, 2007), dimana model ini menempatkan faktor sikap dari tiap-tiap perilaku pengguna dengan dua variabel yaitu kemudahan penggunaan (Ease of use) dan kemanfaatan (Usefulness). Kedua variabel ini dapat menjelaskan aspek keperilakuan pengguna dengan menggunakan 5 (lima) konstruk yaitu persepsi tentang kemudahan penggunaan (Perceived Ease Of Use), persepsi terhadap kemanfaataan (Perceived Usefulness), sikap penggunaan (Attitude Toward Using Technology), perilaku untuk tetap menggunakan (Behavioral Intention To Use), dan kondisi nyata penggunaan sistem (Actual Technology Usage) (Rahman, 2017).

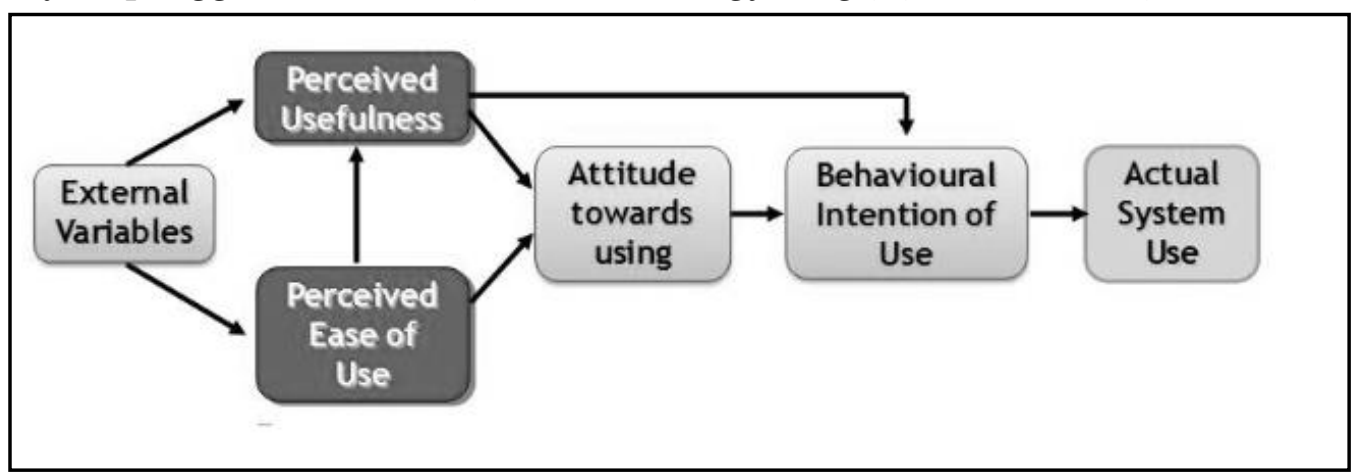

Gambar 1. Model Technology Acceptance Model (TAM)

Sumber : Rahman, 2017

Variabel kemanfaatan adalah kecenderungan seseorang menggunakan atau tidak menggunakan aplikasi karena suatu keyakinan bahwa aplikasi tersebut akan dapat membantu aktivitas agar lebih baik lagi. Variabel kemanfaatan merupakan penentu yang kuat terhadap penggunaan suatu teknologi, adopsi dan perilaku para pengguna (Davis, 1989, Mathinshon, 1991; Venktesh \& Davis, 2000; Sanjaya, 2005). Sedangkan variabel kemudahan adalah tingkat kepercayaan seseorang bahwa penggunaan suatu teknologi akan membebaskannya dari usaha (Sanjaya, 2005). Kemudahan merupakan tingkat dimana seseorang meyakini bahwa penggunaan sistem informasi merupakan hal yang mudah dan tidak memerlukan usaha yang keras dari pemakainya. Konsep ini mencakup kejelasan penggunaan sistem informasi dan kemudahan penggunaan sistem untuk tujuan yang sesuai dengan keinginan pemakai.

Menurut Venkatesh \& Morris (2000), TAM digunakan untuk melihat pemahaman individual yang secara terus menerus menggunakan teknologi informasi dalam aktivitasnya. Penggunaan sistem informasi pada individu untuk melakukan aktivitas dan pemanfaatannya menjadi perhatian penting bagi peneliti, walaupun terdapat kemajuan yang cukup berarti dalam kemampuan hardware dan software. Tujuan TAM adalah untuk dapat menjelaskan faktor-faktor utama perilaku pengguna teknologi informasi terhadap penerimaan pengguna 
teknologi informasi itu sendiri. Model ini menggambarkan bahwa pengguna sistem informasi akan dipengaruhi oleh variabel manfaat dan variabel kemudahan pemakaian dimana keduanya memiliki determinan yang tinggi dan validitas yang telah teruji secara empiris.

\subsection{Sistem Informasi Akademik}

Sistem dapat didefinisikan dari berbagai pendekatan dan beragam istilah. Menurut Lucas (Handayani, 2017), sistem adalah suatu pengorganisasian yang saling berinteraksi, saling tergantung, dan terintegrasi dalam kesatuan variabel atau komponen. Handayani, (2017), mendefinisikan sistem ke dalam dua kelompok pendekatan yaitu menekankan pada prosedur dan komponen atau elemennya. Pendekatan sistem yang lebih menekankan pada prosedur mendefinisikan sistem sebagai suatu jaringan kerja dari prosedur-prosedur yang saling berhubungan, berkelompok, dan bekerjasama untuk melakukan kegiatan pencapaian sasaran tertentu. Pendekatan yang menekankan pada komponen mendefinisikan "sistem" sebagai kumpulan dari elemen-elemen yang berinteraksi untuk mencapai tujuan tertentu.

Informasi adalah arti dari hubungan dan penafsiran data yang mengizinkan seseorang untuk membuat keputusan. Informasi dikatakan berharga jika informasi itu mempengaruhi proses pengambilan keputusan yang lebih baik. Sasaran utama dari sistem informasi adalah menyediakan informasi yang akurat dan penting. Informasi juga dapat berarti beberapa kesatuan yang tak terukur yang dapat mengurangi ketidakpastian tentang suatu peristiwa atau langkah.

Sistem Informasi Akademik (SIA) adalah suatu sistem yang dirancang untuk keperluan pengelolaan data-data akademik dengan penerapan teknologi komputer baik 'hardware' yaitu peralatan-peralatan seperti komputer (PC maupun Laptop), printer, CD ROM, HardDisk, Handphone maupun 'software' atau program komputer yang memfungsikan 'hardware' tersebut, sehingga seluruh proses kegiatan akademik dapat terkelola menjadi informasi yang bermanfaat dalam pengelolaan manajemen perguruan tinggi dan pengambilan keputusan bagi para pengambil keputusan atau top manajemen di lingkungan universitas (Rachman, 2017).

\subsection{Persepsi}

Dalam Kamus Besar Bahasa Indonesia bahwa persepsi adalah tanggapan, penerimaan langsung dari suatu harapan atau merupakan proses seseorang mengetahui beberapa hal melalui panca inderanya. Menurut Muflih (2006) bahwa persepsi adalah proses yang dilakukan individu untuk memilih, mengatur dan menafsirkan ke dalam gambar yang berarti dan masuk akal mengenai dunia. Menurut Veithzal (2007) bahwa persepsi adalah suatu proses yang ditempuh individu mengorganisasikan dan menafsirkan kesan-kesan indera 
mereka. Persepsi itu penting dalam studi perilaku organisasi karena perilaku orang yang didasarkan pada persepsi mereka mengenai apa itu realitas dan bukan mengenai realitas itu sendiri. Jadi persepsi adalah suatu proses pemberian arti kepada stimulus yang dipergunakan oleh seseorang untuk menafsirkan atau memahami dunia sekitarnya dengan cara menyeleksi dan mengorganisasi masukan-masukan serta menginterpretasikannya.

Menurut Baron dan Grenberg (1990) bahwa elemen pembentukan persepsi adalah

a. Informasi dapat berupa benda fisik dan non fisik.

b. Rangsangan yang mendorong pikiran untuk menangkap dan mengolah informasi tersebut.

c. Proses pengolahan informasi yang meliputi pengorganisasian, penafsiran dan pengumpulan makna.

Menurut Rifnaldi (2006) bahwa ada beberapa hal yang harus dipenuhi individu agar dapat mengadakan atau membuat persepsi, yaitu :

a. Adanya objek yang dipersepsikan yaitu objek yang menimbulkan stimulus yang mengenai alat indra atau reseptor.

b. Adanya alat indra atau reseptor yang dapat menerima stimulus.

c. Adanya perhatian untuk mengadakan suatu persepsi tentang suatu obyek yang merupakan langkah pertama dalam mengadakan persepsi.

\section{METODE PENELITIAN}

Penelitian ini dilakukan dalam lingkup manajemen sumber daya manusia dan pendidikan. Penelitian ini adalah penelitian kuantitatif dengan pendekatan deduktif dengan tipe penelitian explanatory serta unit analisisnya adalah individu. Karena penelitian ini penelitian empiris, maka studi kuantitatif menggunakan analisis statistik sangat diperlukan. Sedangkan tipe dari penelitian ini adalah explanatory karena penelitian ini menjelaskan variabel yang diteliti, yang mana variabel dalam penelitian ini diadopsi dari penelitian sebelumnya yang telah diuji.

Tujuannya adalah mengungkap secara luas dan mendalam mengenai persepsi mahasiswa terhadap penggunaan SIA karena SIA ini merupakan salah satu yang sangat vital dalam mendapatkan informasi akademik. Unit analisis dalam penelitian ini adalah mahasiswa yang sudah pernah menggunakan SIA ditempat mereka kuliah. Dalam penelitian ini dilakukan dengan metode analisis deskriptif untuk mengukur persepsi mahasiswa yaitu analisis IPA dan Rentang Skala. Tahapan dari penelitian ini dapat dilihat pada gambar 2 berikut ini : 


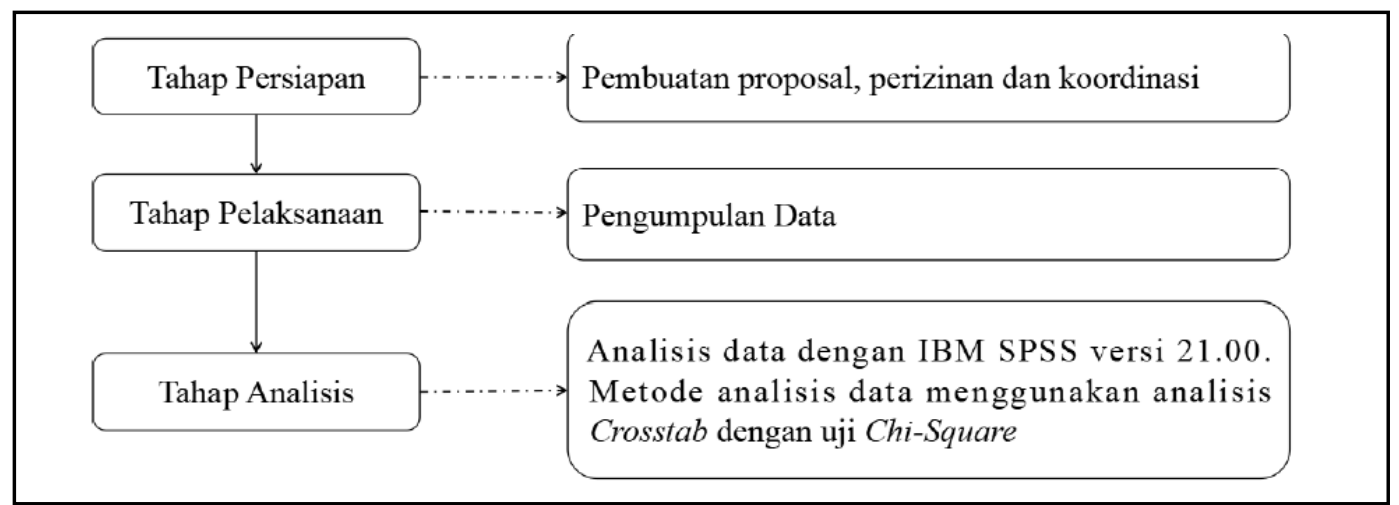

Gambar 2. Tahapan Penelitian

Sumber : Survey, 2019

Kerangka berfikir dalam penelitian ini dapat dilihat pada gambar 3 berikut ini :

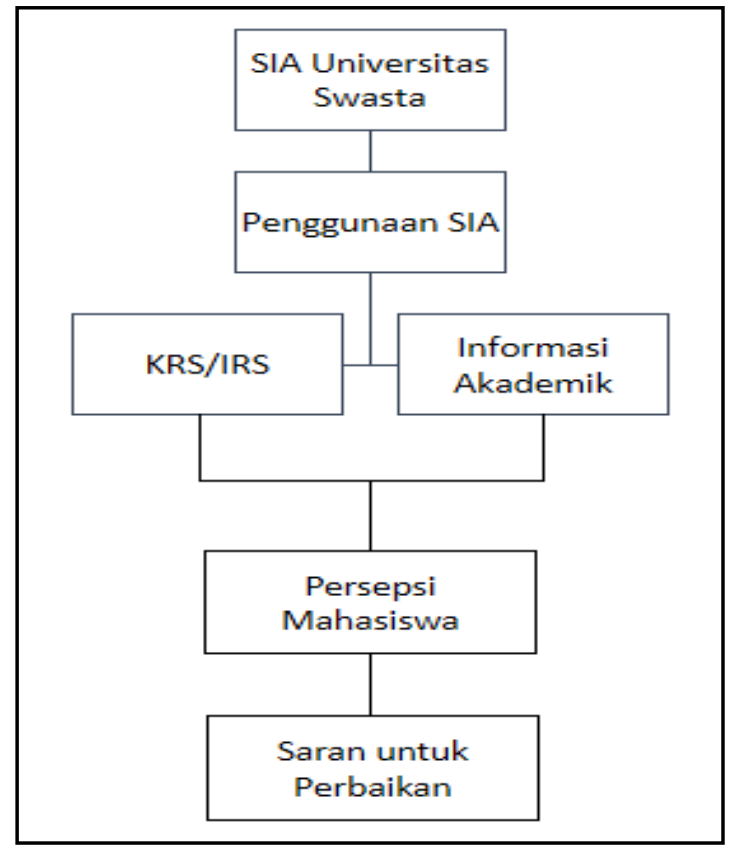

Gambar 3. Kerangka Berfikir

Sumber : Survey, 2019

Sumber data dari penelitian terdiri dari data primer dan data sekunder. Penelitian ini adalah penelitian kuantitatif maka untuk melaksanakannya dilakukan survei kelapangan untuk mendapatkan data primer. Dalam hal ini responden sebagai objek penelitian adalah mahasiswa yang menempuh ilmu di universitas yang ada di kota Padang. Mahasiswa yang dipilih adalah mahasiswa Fakultas Ekonomi dan Bisnis prodi S1 manajemen, minimal yang sudah menggunakan SIA selama 2 semester. Populasinya adalah semua mahasiswa yang ada Fakultas Ekonomi dan Bisnis pada Universitas Dharma Andalas.

Teknik pengambilan sampel dalam penelitian ini menggunakan non probabilitas sampling karena pertimbangan biaya, waktu, dan penerimaan hasil. Dari design non probabilitas sampling maka penelitian ini menggunakan tehnik purposive sampling dengan 
kriteria adalah mahasiswa fakultas ekonomi dan bisnis prodi S1 manajemen yang pernah menggunakan SIA minimal sebanyak 2 kali. Jumlah sampel yang diperoleh sebanyak 61 responden, berasal dari jumlah populasi sebanyak 607 mahasiswa dengan respon rate sebesar 10\%.. Jumlah mahasiswa keseluruhan sebanyak 857 tersebut dikurangi dengan mahasiswa no BP 2018 dan 2019 sebanyak 250 mahasiswa. Hal ini disebabkan mahasiswa tersebut belum memanfaatkan SIA sebanyak 2 kali. Data dikumpulkan dengan menggunakan kuesioner online. Kuesioner online respon rate nya sangat rendah sekitar 10\% - 20 \% (Shih \& Fan, 2009; Schuldt \& Totten, 2005 ).

Variabel yang dinilai berdasarkan teori TAM yaitu persepsi kemudahan penggunaan, persepsi kemanfaatan, sikap penggunaan, minat perilaku penggunaan dan penggunaan sesungguhnya. Teknik analisis data yang digunakan adalah teknik analisis data deskriptif dengan pendekatan kuantitatif yaitu suatu metode dimana data yang diperoleh disusun kemudian diinterpretasikan sehingga memberikan keterangan terhadap permasalahan yang diteliti. Teknik analisis data deskriptif yang digunakan adalah menggunakan analisis Importance Performance Analysis (IPA) untuk mengukur pemetaan layanan dengan tujuan dapat mengetahui persepsi mahasiswa mengenai kualitas pelayanan SIA, sedangkan untuk mengetahui posisi kualitas pelayanan tersebut maka digunakan analisis rentang kriteria. Langkah untuk mengisi diagram kartesius, sebagai berikut:

a. Menjumlahkan nilai kepentingan (Y) setiap variabel dari seluruh pengamatan, kemudian menghitung rata-rata seluruh pengamatan diperoleh rata-rata kepentingan pelayanan $(\bar{Y})$ menggunakan persamaan sebagai berikut :

$$
\bar{Y}=\frac{\sum_{i=1}^{i=n} Y_{i}}{n}
$$

dengan

$\bar{Y} \quad=$ skor rata-rata kepentingan pelayanan

$Y_{i} \quad=$ skor penilaian kepentingan pelayanan pada variabel ke-i

$\mathrm{n} \quad=$ jumlah variabel kepentingan pelayanan

b. Menjumlahkan nilai kepuasan $(X)$ setiap variabel dari seluruh pengamatan, kemudian menghitung rata-rata seluruh pengamatan diperoleh rata-rata kinerja pelayanan $(\bar{X})$ menggunakan persamaan sebagai berikut :

$$
\bar{X}=\frac{\sum_{i=1}^{i=n} X_{i}}{n}
$$

dengan

$\bar{X} \quad=$ skor rata-rata kinerja pelayanan 
$X_{i} \quad=$ skor penilaian kinerja pelayanan pada variabel ke-i

$\mathrm{n} \quad=$ jumlah variabel kepentingan pelayanan

c. Menghitung rata-rata dari rata-rata kepentingan pelayanan yaitu $\overline{\bar{Y}}$.

$$
\overline{\bar{Y}}=\frac{\sum_{i=1}^{i=n} \bar{Y} l}{n}
$$

dengan

$\overline{\bar{Y}} \quad=\quad$ skor rata-rata dari rata-rata kepentingan pelayanan

$\overline{Y_{l}}=\quad$ skor rata-rata kepentingan pelayanan pada variabel ke-i

$\mathrm{n} \quad=$ jumlah variabel kepentingan pelayanan

d. Menghitung rata-rata dari rata-rata kinerja pelayanan yaitu $\overline{\bar{X}}$.

$$
\overline{\bar{X}}=\frac{\sum_{i=1}^{i=n} \bar{X}_{l}}{n}
$$

dengan

$\overline{\bar{X}} \quad=$ skor rata-rata dari rata-rata kinerja pelayanan

$\bar{X}_{2} \quad=\quad$ skor rata-rata kinerja pelayanan pada variabel ke-i

$\mathrm{n} \quad=$ jumlah variabel kinerja pelayanan

e. Membuat diagram dengan menggunakan $\bar{X}$ sebagai sumbu-X dan $\bar{Y}$ sebagai sumbuY.

Memplot hasil rata-rata $(\bar{X}, \bar{Y})$ tiap variabel pada diagram dan membuat dua garis yang saling tegak lurus dan berpotongan pada $(\overline{\bar{X}}, \overline{\bar{Y}})$.

Langkah analisa rentang kriteria, sebagai berikut:

a. Mengelompokkan jawaban

Kuisioner yang terkumpul dikelompokkan sesuai jawaban pada tabel sebagai berikut: 
Tabel 1

Skor dan Skala Likert Kuisioner Penelitian

\begin{tabular}{lll}
\hline Skor & Favorable & Unfavorable \\
\hline 1 & Sangat tidak puas & Sangat puas \\
2 & Tidak puas & Puas \\
3 & Puas & Tidak Puas \\
4 & Sangat puas & Sangat Tidak Puas \\
\hline
\end{tabular}

b. Menghitung Skor

Skor setiap atribut dapat ditentukan dengan rumus berikut :

$$
\text { Skor } \left.=\sum \text { (frekuensi jawaban } \times \text { bobot skala }\right)
$$

c. Menentukan Rentang Skala

$$
R S=\frac{n(m-1)}{M}
$$

dengan :

RS = rentang skala

$\mathrm{n} \quad=$ jumlah sampel

$\mathrm{m} \quad$ = jumlah alternatif jawaban tiap atribut

d. Menentukan Rentang Terendah dan Rentang Tertinggi

$$
\begin{aligned}
& R_{r}=\text { bobot terendah } \times n \\
& R_{t}=\text { bobot terting } i \times n
\end{aligned}
$$

dengan

$R_{r}=$ Rentang Terendah

$R_{t}=$ Rentang Tertinggi

e. Menentukan Skala Penilaian setiap Kriteria

Penentuan skala penilaian setiap kriteria dapat dilihat pada tabel 2 sebagai berikut:

Tabel 2

Rentang Skala setiap Kriteria

\begin{tabular}{lll}
\hline Skala & Tingkat Kepentingan & Rentang Skala \\
\hline $\mathbf{1}$ & Sangat Tidak Setuju & $R_{r}-\left(R_{r}+R S\right)$ \\
\hline $\mathbf{2}$ & Tidak Setuju & $\left(R_{r}+R S+1\right)-\left(R_{r}+2 R S\right)$ \\
\hline $\mathbf{3}$ & Setuju & $\left(R_{r}+3 R S+1\right)-\left(R_{r}+4 R S\right)$ \\
\hline $\mathbf{4}$ & Sangat Setuju & $\left(R_{r}+4 R S+1\right)-R_{t}$ \\
\hline
\end{tabular}




\subsection{Profil Responden}

Responden perempuan lebih banyak dibandingkan responden laki-laki yaitu 60,66 persen berbanding 39,34 persen. Responden yang terpilih paling banyak adalah mahasiswa yang memiliki nomor Pokok Mahasiswa 17 artinya mahasiswa yang sudah berada pada semester 5 (lima) atau mahasiswa yang pertama kali mulai kuliah pada tahun 2017. Selanjutnya, mahasiswa yang memiliki nomor pokok 16 atau mahasiswa yang pertama kali masuk kuliah tahu 2016 dan sekarang sudah berada semester 7. Responden perempuan angkatan 2017 yaitu sekitar 42,62 persen dari keseluruhan responden. Selanjutnya, responden laki-laki angkatan 2017 yaitu sekitar 29,51 persen. Hal ini dapat dilihat pada tabel berikut ini.

Tabel 3

Profil Responden Berdasarkan Angkatan dan Jenis Kelamin

\begin{tabular}{llll}
\hline Angkatan & Laki-Laki & Perempuan & Grand Total \\
\hline $\mathbf{2 0 0 8}$ (BP 08) & $0,00 \%$ & $1,64 \%$ & $1,64 \%$ \\
\hline $\mathbf{2 0 1 5}$ (BP15) & $3,28 \%$ & $1,64 \%$ & $4,92 \%$ \\
\hline $\mathbf{2 0 1 6}$ (BP16) & $6,56 \%$ & $14,75 \%$ & $21,31 \%$ \\
\hline $\mathbf{2 0 1 7}$ (BP17) & $29,51 \%$ & $42,62 \%$ & $72,14 \%$ \\
\hline Grand Total & $39,34 \%$ & $60,66 \%$ & $100,00 \%$
\end{tabular}

Sumber : Data Diolah, 2019

Responden yang terpilih yang memiliki durasi pemakaian jarang dan sangat jarang adalah angkatan 2017 yaitu sekitar 21,31 persen dan 18,03 persen. Sedangkan durasi pemakaian yang sering adalah angkatan 2017 yaitu sekitar 27,87 persen dan yang sangat sering adalah angkatan 2016 yaitu sekitar 6,56 persen. Hal ini dapat dilihat pada tabel berikut ini.

Tabel 4

Profil Responden Berdasarkan Angkatan dan Durasi Pemakaian

\begin{tabular}{llllll}
\hline Angkatan & Sangat Jarang & Jarang & Sering & Sangat Sering & Grand Total \\
\hline $\mathbf{0 8}$ & $0,00 \%$ & $0,00 \%$ & $1,64 \%$ & $0,00 \%$ & $1,64 \%$ \\
\hline $\mathbf{1 5}$ & $0,00 \%$ & $1,64 \%$ & $3,28 \%$ & $0,00 \%$ & $4,92 \%$ \\
\hline $\mathbf{1 6}$ & $1,64 \%$ & $3,28 \%$ & $9,84 \%$ & $6,56 \%$ & $21,31 \%$ \\
\hline $\mathbf{1 7}$ & $18,03 \%$ & $21,31 \%$ & $27,87 \%$ & $4,92 \%$ & $72,14 \%$ \\
\hline Grand Total & $19,67 \%$ & $26,23 \%$ & $42,62 \%$ & $11,48 \%$ & $100,00 \%$
\end{tabular}

Sumber : Data Diolah, 2019.

Responden yang terpilih paling banyak adalah berusia 21 tahun, selanjutnya usia 20 tahun dengan persentase masing-masing adalah 36,07 persen dan 31,15 persen. Dari responden yang terpilih bahwa usia 20 tahun angkatan 2017 adalah responden paling banyak 
yaitu sekitar 29,51 persen dan usia 21 tahun angkatan 2017 yaitu sekitar 22,95 persen. Selanjutnya responden paling sedikit adalah responden berusia 22 tahun angkatan 2008 dan 2015 yaitu masing-masingnya sama sekitar 1,64 persen. Hal ini dapat dilihat pada tabel berikut ini:

Tabel 5

Responden Berdasarkan Angkatan dan Usia

\begin{tabular}{llllll}
\hline Angkatan & 19 Tahun & 20 Tahun & 21 Tahun & 22 Tahun & 23 Tahun \\
\hline $\mathbf{2 0 0 8}$ & $0,00 \%$ & $0,00 \%$ & $0,00 \%$ & $1,64 \%$ & $0,00 \%$ \\
\hline $\mathbf{2 0 1 5}$ & $0,00 \%$ & $0,00 \%$ & $0,00 \%$ & $1,64 \%$ & $3,28 \%$ \\
\hline $\mathbf{2 0 1 6}$ & $0,00 \%$ & $1,64 \%$ & $13,11 \%$ & $3,28 \%$ & $3,28 \%$ \\
\hline $\mathbf{2 0 1 7}$ & $6,56 \%$ & $29,51 \%$ & $22,95 \%$ & $6,56 \%$ & $3,28 \%$ \\
\hline Grand Total & $6,56 \%$ & $31,15 \%$ & $36,07 \%$ & $13,11 \%$ & $9,84 \%$
\end{tabular}

Sumber : Data Diolah, 2019

Dari responden yang terpilih bahwa pesentase paling tinggi adalah responden perempuan yang sering menggunakan SIA Online yaitu sekitar 32,79 persen, selanjutnya persentase responden laki-laki yaitu sekitar 14,75 persen yang jarang menggunakan SIA Online. Hal ini dapat dilihat pada tabel 6 berikut ini:

Tabel 6

Responden Berdasarkan Durasi Pemakaian dan Jenis Kelamin

\begin{tabular}{llll}
\hline Durasi Pemakaian SIA & Laki-laki & Perempuan & Grand Total \\
\hline Sangat Jarang & $11,48 \%$ & $8,20 \%$ & $19,67 \%$ \\
\hline Jarang & $14,75 \%$ & $11,48 \%$ & $26,23 \%$ \\
\hline Sering & $9,84 \%$ & $32,79 \%$ & $42,62 \%$ \\
\hline Sangat Sering & $3,28 \%$ & $8,20 \%$ & $11,48 \%$ \\
\hline Grand Total & $39,34 \%$ & $60,66 \%$ & $100,00 \%$
\end{tabular}

Sumber : Data Diolah, 2019

Dari responden yang terpilih bawa usia 21 tahun palin sering menggunakan SIA Online sekitar 14,75 persen dan sangat jarang adalah responden pada usi 20 tahun yaitu 13,11 persen. Hal ini dapat dilihat pada tabel berikut ini:

Tabel 7

Profil Responden Berdasarkan Usia dan Durasi Pemakaian

\begin{tabular}{llllll}
\hline Usia & Jarang & Sangat Jarang & Sering & Sangat Sering & Grand Total \\
\hline $\mathbf{1 9}$ tahun & $0,00 \%$ & $1,64 \%$ & $4,92 \%$ & $0,00 \%$ & $6,56 \%$ \\
\hline $\mathbf{2 0}$ tahun & $6,56 \%$ & $13,11 \%$ & $11,48 \%$ & $0,00 \%$ & $31,15 \%$ \\
\hline $\mathbf{2 3}$ tahun & $3,28 \%$ & $1,64 \%$ & $4,92 \%$ & $0,00 \%$ & $9,84 \%$ \\
\hline
\end{tabular}




\begin{tabular}{llllll}
\hline $\mathbf{2 1}$ tahun & $8,20 \%$ & $3,28 \%$ & $14,75 \%$ & $9,84 \%$ & $36,07 \%$ \\
\hline $\mathbf{2 2}$ tahun & $6,56 \%$ & $0,00 \%$ & $6,56 \%$ & $0,00 \%$ & $13,11 \%$ \\
\hline $\mathbf{2 6}$ tahun & $0,00 \%$ & $0,00 \%$ & $0,00 \%$ & $1,64 \%$ & $1,64 \%$ \\
\hline $\mathbf{2 7}$ tahun & $1,64 \%$ & $0,00 \%$ & $0,00 \%$ & $0,00 \%$ & $1,64 \%$ \\
\hline Grand Total & $26,23 \%$ & $19,67 \%$ & $42,62 \%$ & $11,48 \%$ & $100,00 \%$
\end{tabular}

Sumber : Data Diolah, 2019

Dari responden yang trpilih bahwa paling banyak adalah responden perempuan berusia 21 tahun dan selanjutnya berusia 2 tahun masing-masingnya 24,59 peren dan 19,67 persen. Sedangkan laki-laki paling banyak berusia sama yaitu 20 tahun dan 21 tahun masing-masing sebesr 11,48 persen. Hal ni dapat dilihat pada tabel 8 berikut :

Tabel 8

Profil Responden Berdasarkan Usia dan Jenis Kelamin

\begin{tabular}{llll}
\hline Usia & Laki-laki & Perempuan & Grand Total \\
\hline $\mathbf{1 9}$ tahun & $0,00 \%$ & $6,56 \%$ & $6,56 \%$ \\
\hline $\mathbf{2 0}$ tahun & $11,48 \%$ & $19,67 \%$ & $31,15 \%$ \\
\hline $\mathbf{2 3}$ tahun & $9,84 \%$ & $0,00 \%$ & $9,84 \%$ \\
\hline $\mathbf{2 1}$ tahun & $11,48 \%$ & $24,59 \%$ & $36,07 \%$ \\
\hline $\mathbf{2 2}$ tahun & $3,28 \%$ & $9,84 \%$ & $13,11 \%$ \\
\hline $\mathbf{2 6}$ tahun & $1,64 \%$ & $0,00 \%$ & $1,64 \%$ \\
\hline $\mathbf{2 7}$ tahun & $1,64 \%$ & $0,00 \%$ & $1,64 \%$ \\
\hline Grand Total & $39,34 \%$ & $60,66 \%$ & $100,00 \%$
\end{tabular}

Sumber : Data Diolah, 2019

Hasil analisis IPA digunakan untuk mengetahui peta persepsi mahasiswa terhadap penggunaan SIA. Dalam hal ini terdapat 5 variabel berdasarkan teori TAM, yaitu variabel kemudahan penggunaan (X1), kemanfaatan penggunaan (X2), sikap penggunaan (X3), minat prilaku penggunaan (X4) dan penggunaan sesungguhnya (X5). Dari hasil analisis IPA diperoleh peta persepsi kelima variabel tersebut pada gambar berikut ini : 


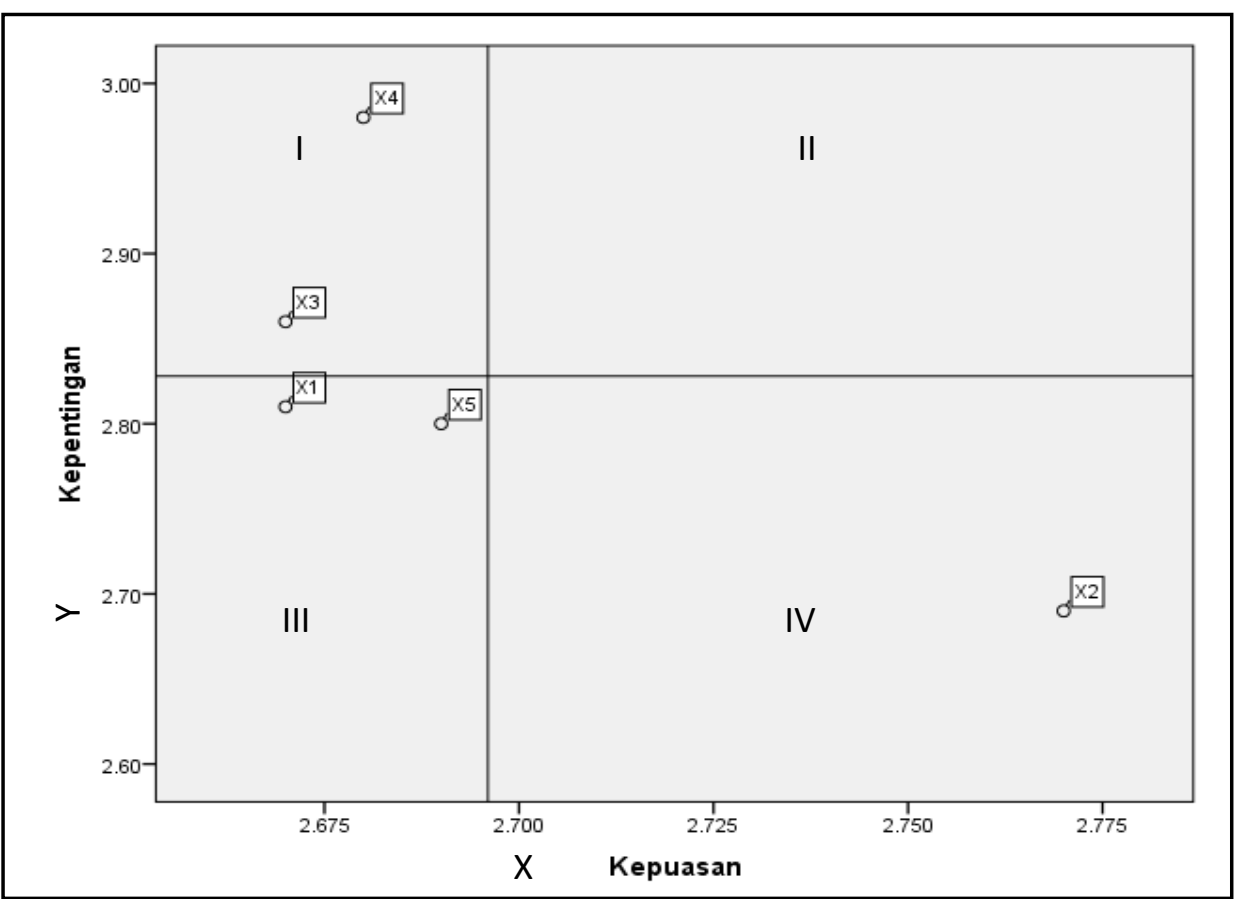

Gambar 4. Peta Persepsi Kuadran IPA

Sumber : Data Diolah, 2019

Dari gambar di atas diperoleh posisi masing-masing variabel di masing-masing kuadran IPA yaitu sebagai berikut:

\section{Tabel 9}

Persepsi Mahasiswa Menggunakan Analisis IPA

$\begin{array}{llllll}\text { No. Variabel } & X & Y & \text { Tingkat Kuadran Keterangan } \\ & & \text { Kesesuaian }\end{array}$

\begin{tabular}{|c|c|c|c|c|c|c|}
\hline X1 & $\begin{array}{l}\text { Kemudahan } \\
\text { Penggunaan }\end{array}$ & 2,67 & 2,81 & $105,09 \%$ & Kuadran 3 & $\begin{array}{l}\text { Prioritas } \\
\text { Rendah }\end{array}$ \\
\hline $\mathrm{X} 2$ & $\begin{array}{l}\text { Kemanfaatan } \\
\text { Penggunaan }\end{array}$ & 2,77 & 2,69 & $97,08 \%$ & Kuadran 1 & $\begin{array}{l}\text { Prioritas } \\
\text { Utama }\end{array}$ \\
\hline $\mathrm{X} 3$ & $\begin{array}{l}\text { Sikap } \\
\text { Penggunaan }\end{array}$ & 2,67 & 2,86 & $107,07 \%$ & Kuadran 4 & Berlebihan \\
\hline $\mathrm{X} 4$ & $\begin{array}{l}\text { Minat Perilaku } \\
\text { Penggunaan }\end{array}$ & 2,68 & 2,98 & $111,01 \%$ & Kuadran 4 & Berlebihan \\
\hline $\mathrm{X} 5$ & $\begin{array}{l}\text { Penggunaan } \\
\text { Sesungguhnya }\end{array}$ & 2,69 & 2,80 & $104,27 \%$ & Kuadran 3 & $\begin{array}{l}\text { Prioritas } \\
\text { Rendah }\end{array}$ \\
\hline
\end{tabular}

Sumber : Data Diolah, 2019

Kuadran 1 adalah prioritas utama yaitu prioritas utama untuk diperhatikan dan diperbaiki. Responden merasa penting namun kinerja yang dirasakan sangat jauh dari harapan (rendah). Dimana tingkat kesesuaian sebesar 97,08\% yang artinya masih terdapat 
sebesar 2,92 persen pelayanan SIA Online yang belum terpenuhi. Variabel ini terdiri dari variabel kemanfaatan penggunaan. Hal yang berkaitan dengan variabel ini adalah SIA tidak efisien dalam melayani keperluan mahasiswa; banyak mahasiswa merasa kesulitan dengan SIA Online; SIA online memunculkan informasi akademik setiap semester; SIA Online menyampaikan pengumuman sebagaimana pengumuman yang ada di papan pengumuman; informasi yang muncul di dalam SIA online selalu update; pengumuman yang disampaikan dalam SIA online lebih awal dari pengumuman secara offline; SIA online memuat informasi yang sudah tidak diperlukan; informasi SIA online sesuai dengan kepentingan mahasiswa; SIA online menyampaikan informasi sesuai kepentingan lembaga; SIA Online Memuat Informasi Yang Cukup Lengkap; dengan adanya SIA Online dapat mengembangkan pembelajaran; SIA Online akan membuat kegiatan belajar lebih baik dari hari ke hari; secara keseluruhan SIA Online bermanfaat bagi dalam studi; menggunakan SIA Online mampu meningkatkan hasil belajar; menggunakan SIA Online mampu meningkatkan hasil belajar; menggunakan SIA Online mampu meningkatkan efektifitas belajar. Jadi menurut responden pengguna masih terdapat kekurangan dari segi manfaat yang dijanjikan.

Selanjutnya, kuadran 2 merupakan prestasi bagi SIA online menurut mahasiswa namun tidak ada variabel yang berada pada kuadran kedua. Artinya pelayanan SIA Online Universitas Dharma Andalas menurut persepsi mahasiswa belum ada yang memberikan kepuasan dalam memberikan informasi akademik dan pelayanan akademik lainnya.

Pada kuadran 3 yang merupakan prioritas rendah yang artinya responden merasa kurang penting dan kinerjanya pun biasa saja. Variabel yang termasuk dalam kuadran ini adalah kemudahan penggunaan dengan tingkat kesesuaian 105,09 persen yaitu kemudahan penggunaan kinerjanya sudah melebihi baik sekitar dan penggunaan sesungguhnya dengan tingkat kesesuaian 104,27 persen. Hal-hal yang terkait adalah Tampilan pelayanan SIA Online komunikatif; tampilan pelayanan SIA Online mudah diakses; tampilan pelayanan SIA Online mudah dipahami; kesalahan input data dalam SIA Online diberitahukan dengan jelas; tampilan menu SIA Online mudah dipahami; tidak ada menu bantuan dalam SIA Online; menu bantuan dalam SIA Online tersedia dengan jelas; sistem menu dalam SIA online sulit dipahami; tampilan website SIA online tidak menarik; tampilan website SIA online tidak menarik; SIA online mudah digunakan; SIA Online tidak menyulitkan mahasiswa; banyak mahasiswa mengeluh dengan SIA Online; SIA Online mudah diakses dengan komputer; SIA Online mudah diakses dengan HP android / smartphone; SIA online hanya dapat dibuka dengan komputer PC; untuk menggunakan fasisitas SIA online tidak memerlukan komputer yang bagus; mahasiswa Dapat Memahami Secara Lengkap Informasi Dari SIA Online; 
informasi Dalam SIA Online Sering Membingungkan Mahasiswa; menggunakan SIA Online mempermudah dalam belajar; Web SIA Online dapat terbuka dalam waktu tidak terlalu lama; Web SIA Online membutuhkan waktu beberapa menit untuk siap digunakan; web SIA online dapat diakses dengan cepat; SIA online dapat dibuka dalam beberapa menit; SIA online dapat digunakan sewaktu-waktu; dan SIA online tidak mengalami gangguan.

Dan kuadran 4 merupakan kuadran yang berlebihan. Responden merasa tidak begitu penting namun kinerja yang dirasakan baik dan lebih sehingga hal ini terlihat mubazir. Variabel yang termasuk dalam kuadran ini adalah variabel sikap penggunaan dan minat perilaku penggunaan dengan tingkat kesesuaian masing-masingnya sebesar 107,07 persen dan 111,01 persen. Hal yang terkait dalam variabel ini adalah saya merasa senang dengan adanya SIA Online Unidha; menggunakan SIA Online menguntungkan bagi saya dalam mengikuti pendidikan; SIA Online membuat waktu saya tidak terbuang percuma dalam mengerjakan tugas-tugas saya; SIA Online memungkinkan saya untuk mengerjakan tugas saya dengan lebih praktis dan efisien Saya lebih senang mengajak teman untuk memanfaatkan SIA Online Unidha; jika ada teman yang tidak paham tentang layanan akademik, saya menyarankan membuka di SIA Online Unidha

Berdasarkan lima variabel di atas maka diperoleh hasil skor msing-mang variabel dengan menggunakan rentang skala yang terbentuk pada tabel berikut ini :

Tabel 10

Interval Rentang Skala

\begin{tabular}{ll}
\hline Tingkat Kepuasan & Rentang Skala \\
\hline Sangat Tidak Memuaskan & $61-106,75$ \\
\hline Tidak Memuaskan & $107,5-152,5$ \\
\hline Memuaskan & $153,5-198,25$ \\
\hline Sangat Memuaskan & $199,25-244$ \\
\hline
\end{tabular}

Sumber : Data Diolah, 2019

Skor yang dihasilkan masing-masing variabel adalah

Tabel 11

Skor Analisis Rentang Skala

\begin{tabular}{llccl}
\hline No. & Variabel & Skor & Rentang Skala & Keterangan \\
\hline X1 & Kemudahan & 167 & $153,5-198,25$ & Memuaskan \\
& Penggunaan & & & \\
\hline X2 & Kemanfaatan & 152 & $107,5-152,5$ & Tidak \\
& Penggunaan & & & Memuaskan \\
\hline X3 & Sikap Penggunaan & 173 & $153,5-198,25$ & Memuaskan
\end{tabular}




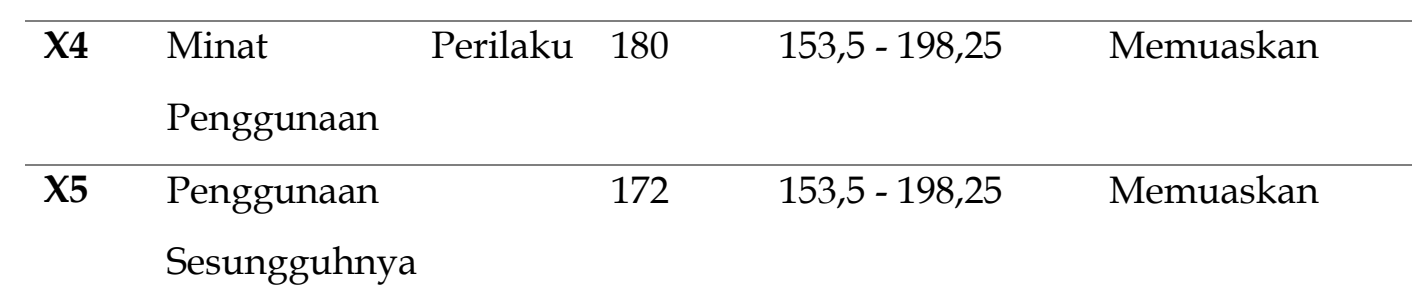

Sumber : Data Diolah, 2019

Dari hasil skor di atas diperoleh bahwa kemanfaatan penggunaan tidak memuaskan bagi responde dalam memberikan pelayanan SIA Online. Hal ini diperoleh skor 152 yang berada pada rentang skala 107,5 - 152,5 dengan penilaian tidak memuaskan.

\subsection{Pembahasan dan Analisis Data}

Responden dalam penelitian ini sebanyak 61 mahasiswa Fakultas Ekonomi dan Bisnis Universitas Dharma Andalas. Keseluruhan mahasiswa tersebut sudah menggunakan SIA Online minimal 2 semester. Hasil penelitian yang diperoleh responden perempuan lebih banyak dibandingkan responden laki-laki dan paling banyak berusia 20 tahun yang masuk kuliah pada tahun 2017. Berdasarkan durasi penggunaan SIA Online, bahwa sebagian besar mahasiwa sering menggunakan SIA Online sering yaitu mahasiswa angkatan 2017. Dan yang paling sering menggunakan adalah responden mahasiswi. SIA Online digunakan paling banyak untuk melihat informasi jadwal kuliah, nilai dan KRS. Sedangkan lainnya adalah untuk melihat tugas yang dipajang diportal mata kuliah.

Berdasarkan hasil analisis IPA diperoleh bahwa variabel kemanfaatan penggunaan menjadi prioritas pertama untuk diperbaiki. Hal ini karena kemanfaatan penggunaan berada pada kuadran 1 dimana kinerja SIA Online rendah dibandingkan persepsi yang diharapkan mahasiswa. Analisis rentang skala juga menunjukkan bahwa variabel kemanfaatan penggunaan memiliki skor 152 yang berada pada rentang 107,5 - 152,5 yaitu rentang tidak memuaskan. Jadi variabel kemanfaatan penggunaan memiliki kinerja yang lebih rendah dibandingkan persepsi mahasiswa.

Hal yang menjadi prioritas paling tinggi bahwa SIA Online tidak efisien dalam melayani keperluan mahasiswa dan banyak mahasiswa merasa kesulitan dengan SIA Online. SIA online memuat informasi yang sudah tidak diperlukan, untuk itu sebaiknya setiap hari selalu mengecek ulang dan update informasi penting di SIA Online.

Selanjutnya, pengumuman yang disampaikan di SIA Online sama dengan pengumuman yang ada di papan pengumuman bahkan lebih awal agar SIA Online menjadi yang utama untuk dimanfaatka oleh mahasiswa. Dalam hal pemanfatan SIA Online sebagai pembelajaran masih rendah. Hal ini dikarenakan sistem masih belum sempurna dan kurangnya panduan dalam memanfaatkan pembelajaran secara daring menggunakan SIA 
Online. Untuk itu sebaiknya, agar SIA Online dapat dimanfaatkan secara efektif dan efisien, maka perguruan tinggi harus menyediakan sumber daya manusia yang mampu mengelola sistem, melakukan update informasi, memberikan bimbingan mengenai pengelolaan SIA Online ke dosen dan mahasiwa serta tenaga pendidik. Sumber daya manusia yang disediakan lebih dari satu orang agar mereka bisa lebih fokus dalam mengelola dan memperbaiki sistem. Sistem tersebut diharapkan dapat terintegrasi dan dimanfaatkan untuk perkuliahan secara daring atau online terutama pada saat pandemi COVID 19 ini. Dikarenakan hampir semua kegiatan pada saat pandemi COVID-19 ini dikerjakan secara online menggunakan internet.

\section{KESIMPULAN}

Penelitian pada mahasiswa Fakultas Ekonomi dan Bisnis Universitas Dharma Andalas diperoleh hasil sebagai berikut terdapat responden laki-laki yang lebih banyak dibandingkan perempuan, namun yang sering menggunakan SIA Online untuk melihat jadwal kuliah, mengisi KRS, melihat soal tugas. Selanjutnya, terdapat lima variabel yang mengukur persepsi mahasiswa mengenai kinerja SIA Online yaitu variabel Kemudahan Penggunaan, Kemanfaatan Penggunaan, Sikap Penggunaan, Minat Perilaku Penggunaan dan Penggunaan Sesungguhnya. Pada variabel kemanfataan penggunaan menjadi prioritas utama untuk diperbaiki karena berada pada kuadran pertama di Kuadran IPA dan variabel kemanfaatan penggunaan memiliki skor 152 yang berada pada rentang tidak memuaskan

\section{DAFTAR PUSTAKA}

Davis, Fred D. (1989), "Perceived Usefulness, Perceived Ease of Use, and User Acceptance of Information Technology", MIS Quarterly ,Vol. 13, No. 3 , pp. 319-340.

Fitriani, Ika Nurul (2012), “Persepsi Mahasiswa Program Studi S1 Ilmu Perpustakaan Universitas Diponegoro Terhadap Penggunaan Sistem Informasi Akademik Universitas Diponegoro (SIA Undip)", Jurusan Ilmu Perpustakaan, Fakultas Ilmu Budaya, Universitas Diponegoro, Indonesia, Vol 1, No. 1.

Handayani. Muslih Aris (2017), “Tinjauan tentang Persepsi Mahasiswa terhadap Pelayanan Sistem Informasi Akademik IAIN Purwokerto", KOMUNIKA, Vol. 11, No. 2.

M., Jogiyanto H. (2007), Analisis dan Desain Informasi, Yogyakarta: Andi Offset.

Kristiawan, dkk. (2016), “Kepuasan Pengguna Sistem Informasi Akademik (Siakad Online)

Di FKIP UNS dan Pengaruhnya terhadap Manfaat Peningkatan Kualitas

Pembelajaran", Jurnal Pendidikan Bisnis dan Ekonomi, Vol. 2, No 1. 
Mathieson, K. (1991), “Predicting User Intentions: Comparing the Technology Acceptance Model with the Theory of Planned Behavior", Information Systems Research, Vol. 2, pp. 173-191, available at: http://dx.doi.org/10.1287/isre.2.3.173

Muflih, Muhammad (2006), Perilaku Konsumen Dalam Persepektif Ilmu Ekonomi Islam, Jakarta: Rajawali.

Rachman, Yudi (2017), “Analisis Penerimaan Sistem Informasi Akademik oleh Dosen dengan Menggunakan Technology Acceptance Model (TAM)", Jurnal LPKIA, Vol. 10 No. 2.

Sanjaya, I Putu Sugiartha (2005), “Pengaruh Rasa Manfaat dan Kemudahan terhadap Minat Berperilaku (Behavioral Intention) Para Mahasiswa dan Mahasiswi dalam Penggunaan Internet", Kinerja, Vol. 9, No. 2, pp. 113-122.

Schuldt, B. A., \& Totten, J. W. (2005), “Electronic Mail versus Mail Survey Response Rates”, Marketing Research, Vol. 6, No. 1, pp. 36-39.

Sevima, (2019), available at: https://sevima.com/manfaat-sistem-informasi-akademikbagi-perguruantinggi-mahasiswa/ (20 Juni 2019).

Shih, T., \& Fan, X. (2009). “Comparing Response Rates in E-mail and Paper Surveys : A Metaanalysis". Educational Research Review" ", Vol. 4, No. 1, pp. 26-40, available at: http://doi.org/10.1016/j.edurev.2008.01.003.

Sultono, dkk. (2015), “Analysis on Academic Information System Quality Toward User Satisfaction", International Journal of Administration Science, Vol. 22, No 2.

Veithzal, Rivai (2007), Kepemimpinan dan Perilaku Organisasi , PT. Raja Grafindo Persada. Venkatesh, V. dan Davis, F.D. (2000), “A Theoretical Extension of the Technology Acceptance Model: Four Longitudinal Field Studies". Management Science, Vol. 46, No. 2, pp. 186-204.

Venkatesh, V \& Morris, M.G. (2000), “Why Don't Men Ever Stop to Ask for Direction? Gender, Social Influence and Their Role in Technology Acceptance and Usage Behavior", MIS Quarterly, Vol. 24, No. 1, pp. 115-139. 